\title{
IoT Based Hygiene Monitor for Senior Citizens and Mentally Challenged
} Mounica B, Yashaswini S, Charitha V, Varsha Gowda S J , Judy Kennedy

Department of Information Science and Engineering, New Horizon College of Engineering, Bangalore (Dist.), Karnataka, India

\section{Article Info}

Volume 7, Issue 4

Page Number: 223-229

\section{Publication Issue :}

July-August-2021

\section{Article History}

Accepted : 10 July 2021

Published : 18 July 2021

\section{ABSTRACT}

Advancements in medical science and technology, medicine and public health coupled with increased consciousness about nutrition and environmental and personal hygiene have paved the way for the dramatic increase in life expectancy globally in the past several decades. However, increased life expectancy has given rise to an increasing aging population, thus jeopardizing the socio-economic structure of many countries in terms of costs associated with elderly health-care and well- being. In order to deal with the growing need for elderly health-care services, it's essential to develop affordable, unobtrusive and easy-to-use health-care solutions. In this paper, we focused on smart diapermoisture detection system using IOT. It is a paper based expendable dampness initiated Wi-Fi specialized gadget that could be fused into the conventional cellulose-based diaper. The Wi-Fi enabled sensor unit is done for minimal expense producing, low radiation uses $\mathrm{Wi}-\mathrm{Fi}$ to send notification to authorized person. There are various approaches to distinguish and quantify dampness where a few models already exist, despite the fact that most strategies require dynamic hardware. When the diaper gets genuinely wet, the dampness sensor turns into source that takes care of an oscillator circuit. The power of the transmitted Wi-Fi connection is far below the levels where it could cause any harm to human.

Keywords : Health-care, Wi-Fi enabled, Cellulose-based, Dampness, Moisture Detection, Public Health

\section{INTRODUCTION}

With demographic transition underway in India, the elderly population has projected to rise to $12 \%$ of the entire population by 2025. The ever-increasing elderly population poses social and financial challenges and puts immense strain on the health system thanks to marked shift toward chronic noncommunicable diseases. Besides, social factors like fewer children in each family, increased employment opportunities for ladies, who were traditionally taking care of the old in India, rapid urbanization and rise of nuclear families involve more specialize in geriatric issues, both medical and socioeconomic. The 
elderly in India are a heterogeneous population with variations in morbidity across several variables like gender, location and socioeconomic status as wide diversity in culture and religion. At least $65 \%$ of India's old are illiterate and dependent.Thus, there is a requirement to deal with the medical and socioeconomic problems of this vulnerable group and promote healthy ageing.

The advent of the Internet of Things and miniaturization of sensing devices has accelerated the growth of wearable health devices, with an estimated economic impact of

$\$ 0.2 \mathrm{~T}$ by 2025 . Devices such as smart textiles and smart watches are already in use for real-time selfcare and predictive health-care applications by monitoring physiological conditions such as blood pressure, body temperature, respiration rate, and perspiration rate. As sensing, communication, and remote patient monitoring infrastructure become pervasive, the data contained in diaper waste may enable predictive health care and at- point diagnostics. In today's world, where health and cleanliness are intertwined urinary incontinence afflict convalescent individuals and infants who are dependent on their caregivers. The elderly may suffer incontinence resulting from nerve deterioration or conditions including Alzheimer's or dementia. If diaper wearers are left unattended, they may suffer from rashes, discomfort, and bacterial infection.The incontinence problems do not only relate to patients who suffer but also affect the primary careers. Various assessment and treatments available to the incontinent patients are reported in. The evaluation of various incontinent products and devices available in the markets has been done in, but none of those products found viable solution to manage incontinence. A non- technical method, behavioral intervention, proved its usefulness in normal nursing home population.

According to our research, there is still lacking for an accessible assertive solution for careers in managing incontinence in nursing homes. Usually, people with irreversible incontinence factors have to wear diaper all the time to avoid potential medical and social implications. Nevertheless, timely diaper change is required to avert the problems of staying in soiled diapers. They usually do not have self-ability to notice and notify the careers of being incontinent. Ideally, carers must know who is incontinent and attend to people with soiled diaper without delays. Nevertheless, incontinence episodes can occur at anytime; there is no fixed or regular timing. This requires carers to check diaper wetness from one patient to another and to perform these scheduled diaper checks at every specified interval. This approach is time consuming, labor intensive and causing annoyances to the patients as well as carers. Therefore, it is not feasible and effective to provide round the clock care to multiple incontinent patients in this demands the use of pervasive solution assisting carers by notifying incidence of incontinence episodes of the patients in order to provide desirable level of continence management.

The focus of this paper is to present our works on developing a solution for effective continence management through wetness alert diaper, the diapers with embedded sensors could alert caregivers of when a diaper needs to be changed, therefore, it is critical to notify the caretaker via their mobile phones when the diaper is totally wrung out. This increases the quality of life of diaper wearers. The technology would ultimately save time and money by optimizing usage while reducing potential embarrassment for diaper wearers and also could improve health and prevent health conditions at a lower cost. 


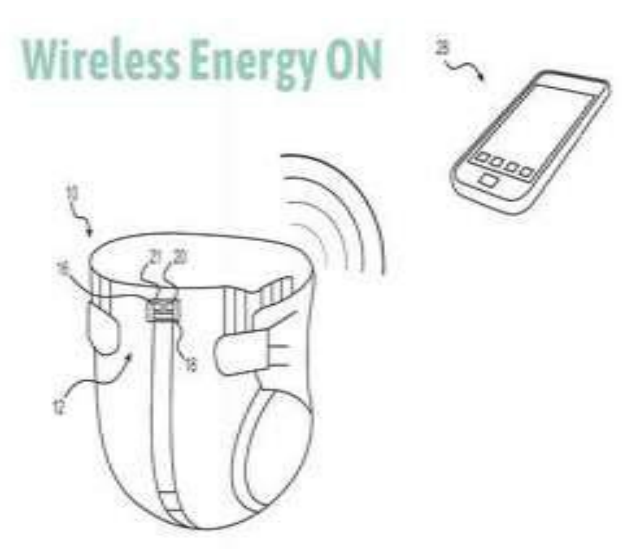

Figure 1 : Smart Diaper.

\section{LITERATURE REVIEW}

There is considerable amount of work within the literature regarding the usage of the web of Things to deliver health services. Usak et al conducted a scientific literature review on the usage of Internet of Things in health care systems. The work also included an in depth discussion of the most challenges of using IoT to supply health services, and a classification of the reviewed add the literature.

$\mathrm{Wu}$ et al. worked on a hybrid IoT safety and health monitoring system. The goal was to improve outdoor safety. The system consists of two layers. one is employed to collect data from the user, and thus the opposite to aggregate the collected data over the online. Wearable devices were familiar with collect safety indicators from the encircling environment, and health signs from the user. Amna Abdullah and et al. demonstrate a LabVIEW based patient checking framework. The framework undertaking will be done in five different key advances. We expect about two frameworks to execute the system. During this system, we see the sensors attached with the patient's body to a transmit unit related with a ZigBee or GSM orchestrate. The transmitter transmits the info remotely to a recipient that's additionally connected with a ZigBee or GSM engineer. The beneficiary is connected on to the USB port of an in depth to watching unit (which might be a Laptop with LabVIEW programming in it).

In remote health monitoring system, the patient's health parameters are recorded by a wise phone by eliminating an extra hardware and transmit data through an online interface. It gives end to finish monitoring screen through three main steps. Firstly, the most important one, time health parameters are measured through wearable sensors and transmitted to a wise phone which shows the patient health status in graphical interface. Secondly, this system sends information to friends and doctor through web interface for further monitoring of the user. Lastly, It provides real time alarm if the patient is at emergency situation like attack, etc

\section{METHODOLOGY}

A. Components and Specification

1. NODE MCU/ESP8266

The ESP8266 is a micro controller built by Espressif Systems that has Wi-Fi built in. There are a variety of methods to program the ESP8266 including:

$\checkmark$ AT (terminal) commands

$\checkmark$ Official ESP8266 SDK and Tool chain

$\checkmark \quad$ NodeMCU with eLua

$\checkmark$ Arduino IDE

Programming of ESP8266 in Arduino was adopted for this work, which provides access to most of the libraries found in the Arduino IDE environment as well as a very well understood development process for IoT devices. The ESP8285 is an ESP8266 with 1 $\mathrm{MB}$ of built-in flash, allowing for single-chip devices capable of connecting to Wi-Fi. 


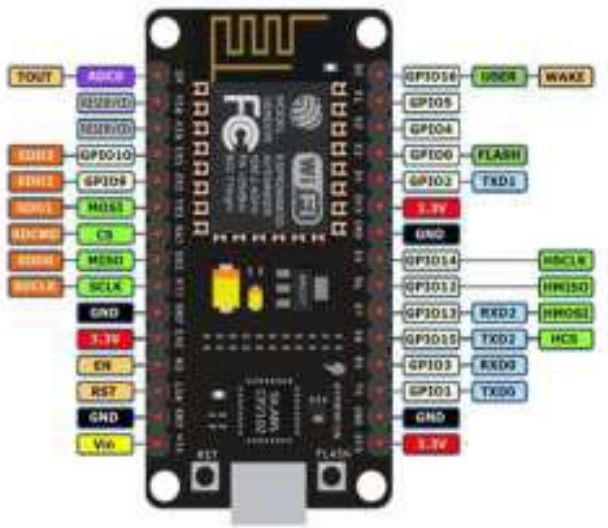

Figure 2: Pin Details of ESP8266

\section{SOIL MOISTURE SENSOR}

The soil moisture sensor measures the volumetric content of water in the soil. The soil moisture sensor uses the capacitance to measure the volumetric content of water present in soil. Since the direct gravimetric measurement of free soil moisture requires removing, drying, and weighing of a sample, moisture sensor measures the volumetric content of water indirectly by using some property of soil, like electrical resistance, interaction with neutrons interaction, as a proxy for the moisture content. This is the main reason to use this sensor in diverse fields such as botany, biology, horticulture and mainly in soil science.

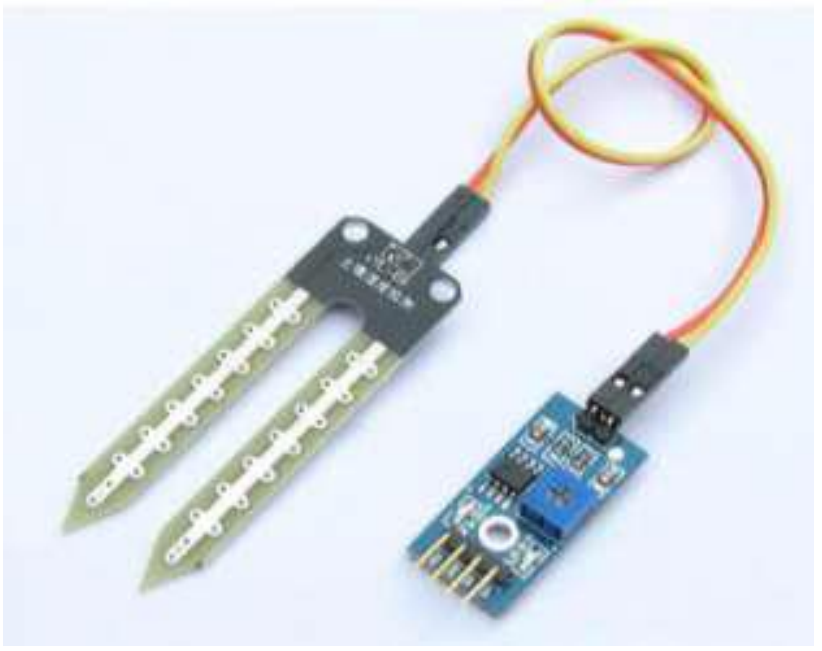

Figure 3: Soil Moisture Sensor

\section{5 V BATTERY}

A battery is a power source containing one or more electrochemical cells that have an external connection to power electrical devices such as flashlights, cell phones, and electric vehicles. When a battery provides power, its positive terminal is the cathode and it's no anode terminal. The signal as negative is a source of electrons that will travel through an external electrical circuit to a positive circuit. When a battery is connected to an external power line, the redox reaction converts high-power generators into low-power products, and the free energy difference is introduced into the external circuit, as electrical power is one cell.

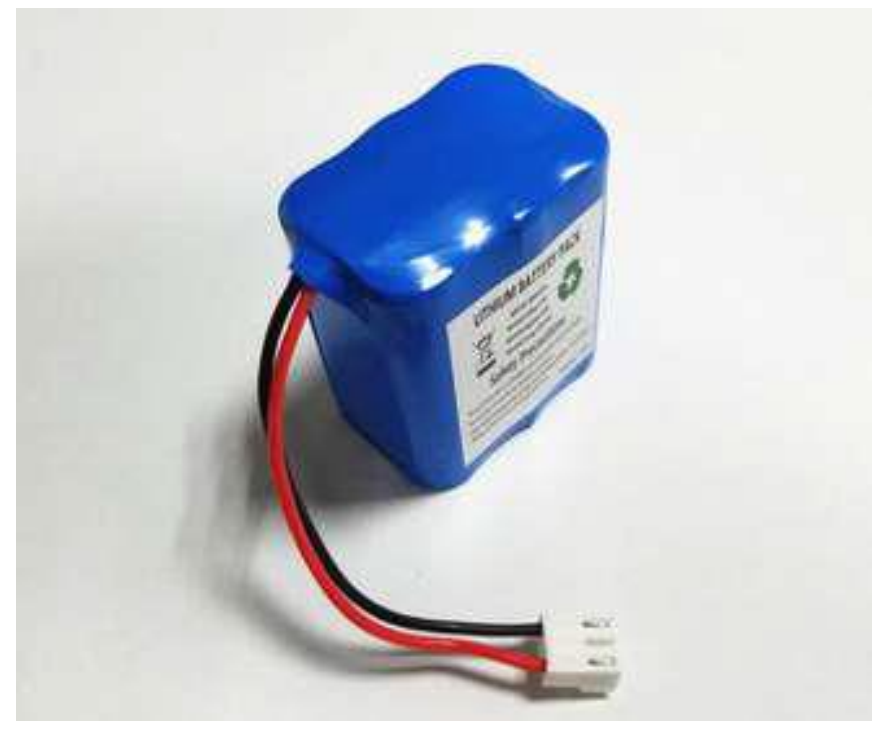

Figure 4: 5 V Battery

\section{DESIGN AND WORKING}

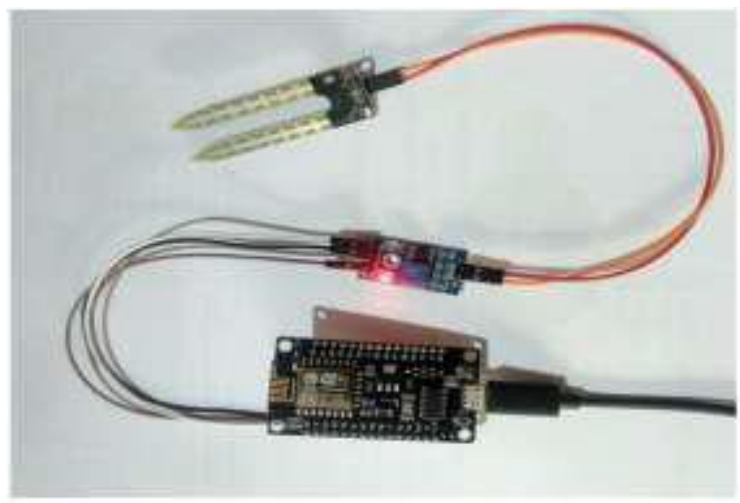

Figure 5: Circuit Connection. 


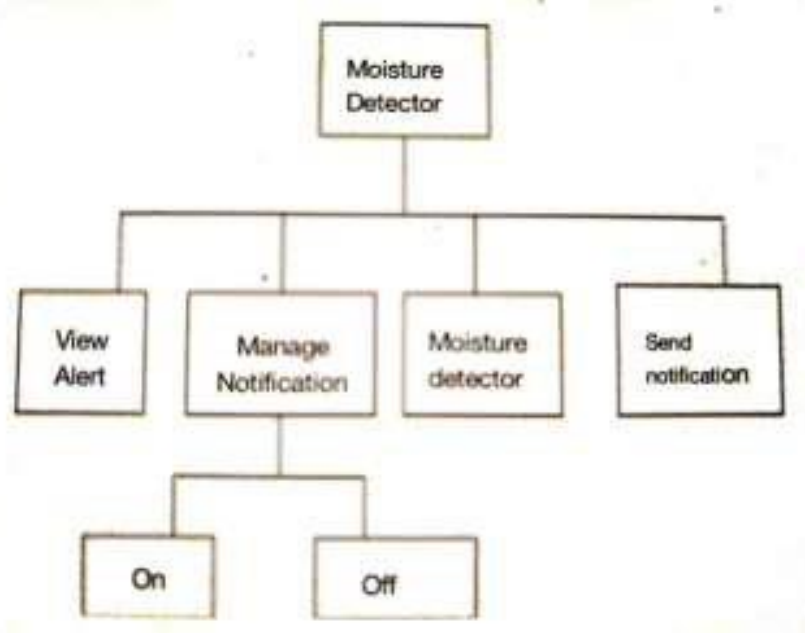

Figure 6: Modular Design

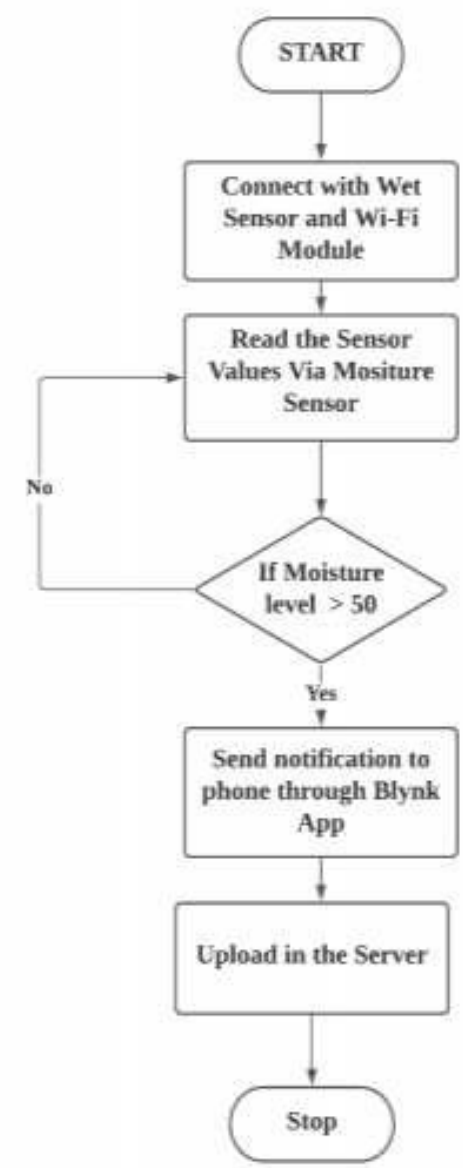

Figure 7 : Workflow

\section{EXPERIMENTAL RESULTS}

The suggested wet detector was put to the test. The developed wet detector is connected to a printed conductor tag within the diaper. The sensitivity of the moisture detector may be changed by looking at the Arduino serial monitor voltage, which comes from the ADC. The voltage drop seen in Fig.6 varies depending on the amount of pee within the diaper. Instead of pee, we used water. Six different diapers with $1 \mathrm{ml}, 2 \mathrm{ml}, 3 \mathrm{ml}, 4 \mathrm{ml}, 5 \mathrm{ml}$, and $6 \mathrm{ml}$ of water inside are used to evaluate the wet detector's performance. The wet detector is fastened to the diaper by pressing studs, which connects the wet detector to the printed conductor within the diaper, as illustrated in Fig.8. By pushing stud, the user may simply change the separate wet detector.

\section{COM3}

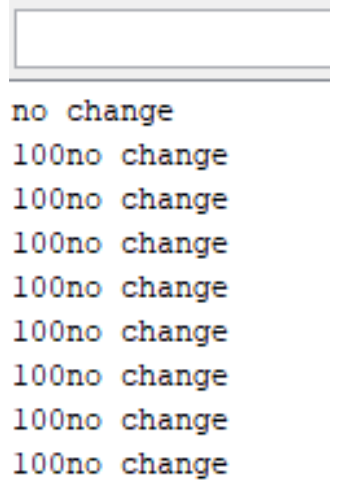

Figure 8: Experimental Result on Serial Monitor

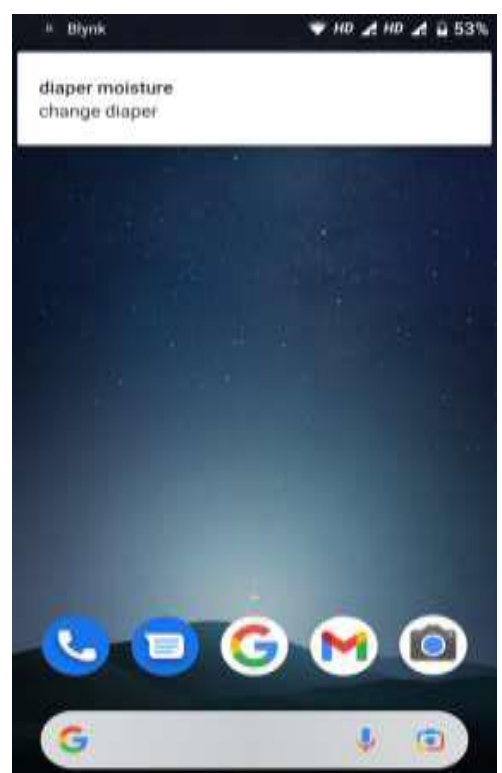

Figure 9: Experimental Result on Mobile Phone 


\section{CONCLUSION}

The diaper's wearer health is vital for parent and family member. Sometimes Wet diaper causes a dangerous health problem. During this paper proposed a wet diaper detector based on smart phone, sensor and Wi-Fi module.Above experimental results shows that proposed method is extremely convenient to detect wetness of the diaper send notifications to mobile phone and it is also optimized for low cost, easy handle and low EM radiation. This smart diaper is intended for hospitals and elderly care units, where the small extra cost per the diaper may pay itself back in decreased working time, and increase the quality of service for the patients and this system is well suited for incorporating into existing intelligent healthcare. Thus, through this, we can conclude by saying that it is better to have such upgraded diapers, which are very helpful and such diapers will help the caretakers to have a stress less life.

\section{FUTURE ENHANCEMENT}

The freshest pattern in the shrewd diapers market is diaper alert with advanced cell application that cautions guardians when elderly person wet the diaper. The idea of following a person's wellbeing through keen diapers has begun to be abused industrially. Shrewd grown-up diapers uncover issues like urinary plot contamination, delayed lack of hydration, and creating kidney issues.

The worldwide brilliant diaper market can be fragmented based on demography, application, and topography. In light of demography, the market can be divided as child diapers and grown-up diapers. As indicated by application, the market can be divided as all-inclusive consideration, local area care, and clinical consideration. As far as geology, the worldwide savvy diaper market can be fragmented into North America, Europe, Asia Pacific, Middle East and Africa, and South America

\section{REFERENCES}

[1]. Johan Siden, Andrei Koppioug and Mikael Gulliksson "The diaper moisture detection system" MidSweden University, Electronics department, 2004.

[2]. Aung Aung Phyo Wai, Foo Siang Fook and Jit Biswas "Towards Developing Effective Continence Management through Wetness Alert Diaper" Institute for Infocomm Research,Singapore,2010.

[3]. Mohamed Y.E Simik, Feng Chi, Randa S.I.Saleh "A Design of Smart Diaper Wet Detector using Wireless and Computer", 2015.

[4]. MD Saifur Rhman,Chulhyung Choi,Youngpil Kim "A Low Cost Wet Diaper Detector Based on Smart Phone and BLE Sensor", Kongju National University, Department of Electrical ,Electronic and Control Engineering,2017.

[5]. Mohamed Y. E. Simik, Feng Chi, Randa S. I .Saleh, and Abdeldime M.S. Abdelgader -A Design of Smart Diaper Wet Detector Using Wireless and Computing - Proceedings of the World Congress on Engineering and Computer Science 2015 Vol II WCECS 2015, October 2123, 2015, San Francisco, USA

[6]. Rajesh M.Nair,9 Saxford LA. Patent number 5568128. Self learning diaper wetness detector and toilet trainer.

[7]. D.Pamela,K.Gerard,Kngston Stanley, "Wet Diaper Alert System For Bedside Patients with Wireless Communication to Nursing Station via Smart Diaper Mobile Application”, Department of Electronics and Instrumentation Engineering, 2018.

[8]. S.Sanjal, Y.Atanasov,B.D.Braaten, "A Low Cost Flexible Passive UHF RFID Tag for Sensing Moisture Based on Antenna Polarization, North 
[9]. M. Y. E. Simik, F. Chi, A. M. S. Abdelgader, and

R. S. I. Saleh, -Automated alarm system for diaper wet using GSM, $\|$ in Proceedings - 17th IEEE International Conference on Computational Science and Engineering, CSE 2014, Jointly with 13th IEEE International Conference on Ubiquitous Computing and Communications, IUCC 2014, 13th International Symposium

\section{Cite this article as :}

Mounica B, Yashaswini S, Charitha V, Varsha Gowda S J , Judy Kennedy, "IoT Based Hygiene Monitor for Senior Citizens and Mentally Challenged", International Journal of Scientific Research in Computer Science, Engineering and Information Technology (IJSRCSEIT), ISSN : 24563307, Volume 7, Issue 4, pp.223-229, July-August2021. Available at doi : https://doi.org/10.32628/CSEIT217458 Journal URL : https://ijsrcseit.com/CSEIT217458 